\title{
Groundwater Potential Zones in Relation to Catchment Condition in Orenburg, Russia
}

\author{
K Choudhary ${ }^{1,2,3}$, M S Boori ${ }^{1,3,4}$ and A Kupriyanov ${ }^{1,5}$ \\ ${ }^{1}$ Samara National Research University, Moskovskoe Shosse 34A, Samara, Russia, 443086 \\ ${ }^{2}$ The Hong Kong Polytechnic University, Hong Kong \\ ${ }^{3}$ University of Rennes 2, Rennes, France \\ ${ }^{4}$ American Sentinel University, Colorado, USA \\ ${ }^{5}$ Image Processing Systems Institute of RAS - Branch of the FSRC "Crystallography and \\ Photonics" RAS, Molodogvardejskaya street 151, Samara, Russia, 443001 \\ e-mail: komal.kc06@gmail.com
}

\begin{abstract}
The main objective of this study was to detect groundwater availability for agriculture in the Orenburg, Russia. Remote sensing data (RS) and geographic information system (GIS) were used to locate potential zones for groundwater in Orenburg. Diverse maps such as a base map, geomorphological, geological structural, lithology, drainage, slope, land use/cover and groundwater potential zone were prepared using the satellite remote sensing data, ground truth data, and secondary data. ArcGIS software was utilized to manipulate these data sets. The groundwater availability of the study was classified into different classes such as very high, high, moderate, low and very low based on its hydro-geomorphological conditions. The land use/cover map was prepared using a digital classification technique with the limited ground truth for mapping irrigated areas in the Orenburg, Russia.
\end{abstract}

\section{Introduction}

Groundwater is a form of water occupying all the voids within geological layers. The occurrence of groundwater in a geological formation and the scope for its absorption primarily depend on the formation porosity. The conventional methods used to prepare groundwater potential zones are mainly based on ground surveys. The groundwater conditions are significantly depending upon the slope, surface water body, depth of weathering, canals and irrigated fields, etc. These factors can be interpreted in remote sensing data. Minor et al. [1] developed an integrated interpretation strategic to characterize groundwater resources for identification of well location in Orenburg using GIS. Gustafson [2] used GIS for the analysis of lineament data received from SPOT imagery for groundwater potential mapping. Krishnamurthy et al. [3] developed a GIS-based model to describe groundwater potential zones. The field verification of this model established the efficacy of GIS in demarcating the potential groundwater reserves.

A GIS framework was developed and analyzed by Das et al. [4] with rational conditions to groundwater zones using thematic layers like geomorphology, geology, drainage, slope and land use/cover generated by ArcGIS software. Based on the status of groundwater irrigated areas through remote sensing artificial recharge structures such as tanks, dams can be recommended upstream of groundwater irrigated areas to recharge wells in the downstream areas to increase groundwater resources [5]. 
Previous studies show a wide range of using remote sensing (RS) and geographical information system (GIS) technology for groundwater potential zone (GWPZ) assessment. In that, they use different thematic layers, give specific weight to all classes and each thematic layer based on their sensitivity or specific importance on groundwater potentiality. In this paper, we use RS and GIS technology, create different thematic layers, which are responsible for groundwater possibility and then give specific weight. This research work confirms conservation of sustainable aquifer development judicious extraction of dynamic groundwater resource available in the Orenburg of Russia [6].

\section{Study area}

We choose the east part of Orenburg Oblast, Russia (figure 1) as a study area. It's situated on the boundary of Europe and Asia on Ural rives with Kazakhstan border. The study area latitude is $51^{\circ} 77^{\prime}$ and longitude $55^{\circ} 10^{\prime}$ with 107 meters above sea level elevation. Orenburg has a relatively dry humid continental climate with long hot summers and long cold winters. The average January temperature is $-15.6^{\circ} \mathrm{C}\left(3.9^{\circ} \mathrm{F}\right)$ and the average July temperature is $29.0^{\circ} \mathrm{C}\left(84.2^{\circ} \mathrm{F}\right)$. The most important river of the Oblast is the Ural River.

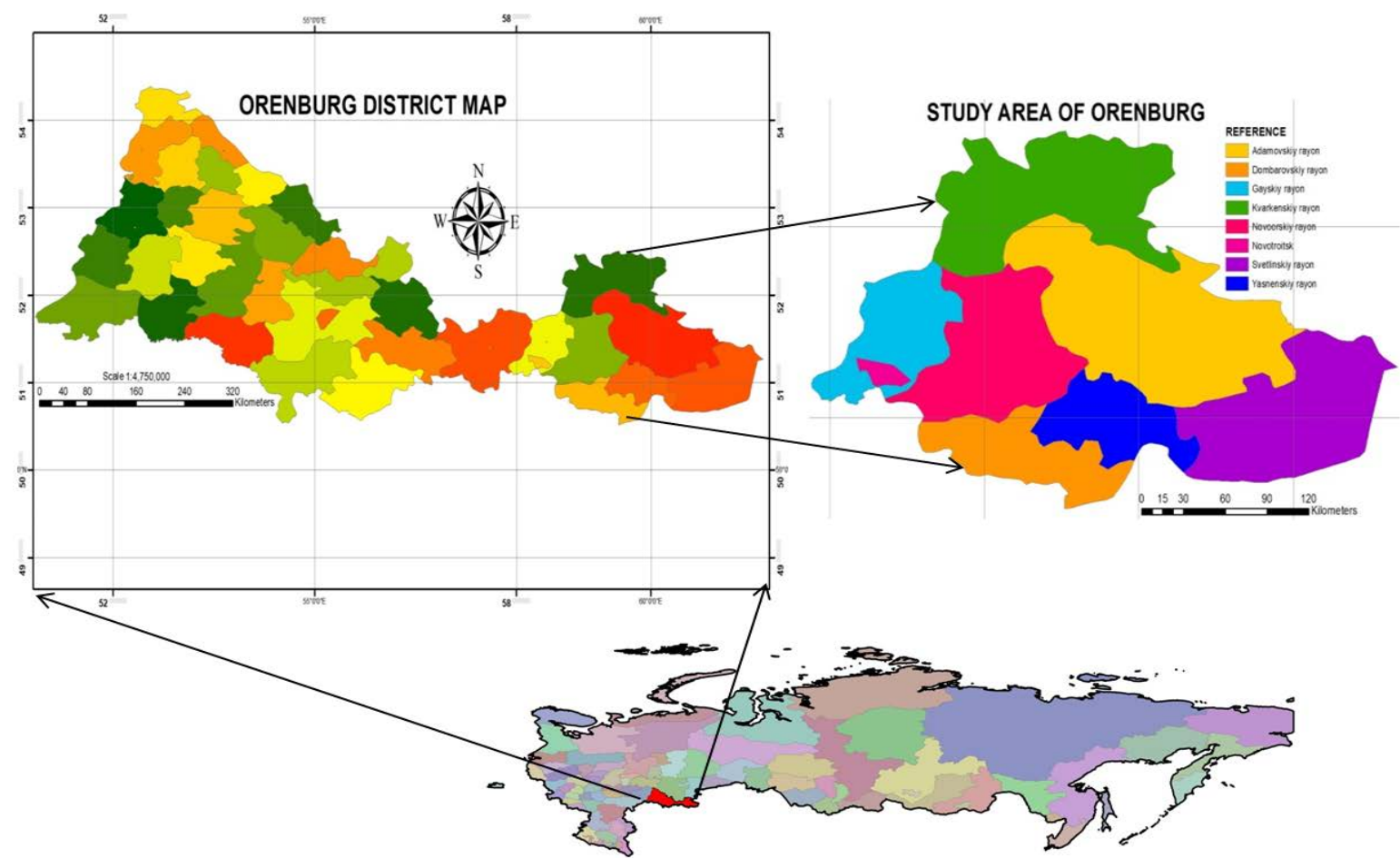

Figure 1. Location map of the Orenburg, Russia.

\section{Materials and methods}

This research work used Landsat-8/OLI (Operational land imager) images to make different thematic layers such as agriculture, forest, geomorphology, land use, lithology, soil, land use/cover, surface water, drainage density, flow accumulation, flow direction, and base map. Also, use Digital Elevation Model (DEM) from ASTER satellite (ASTER-GDEM) with the 30m spatial resolution to create a slope map for height information. We use ArcGIS and ERDAS software for all types of image processing and GIS analysis work. For accuracy assessment and verify our results we used ancillary data, topographic maps, field data and specific government departmental information's.

In methodological steps after georeferenced the imagery in UTM/WGS84 projection, we remove radiometric and geometric errors [7]. Then identify best band combination for image interpretation and create following thematic layers (figure 2). 


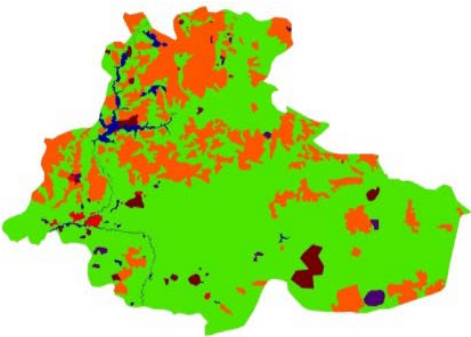

Land use/cover

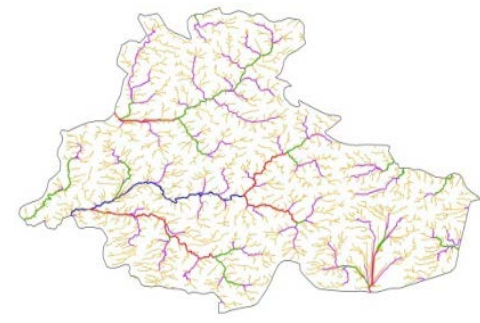

Drainage

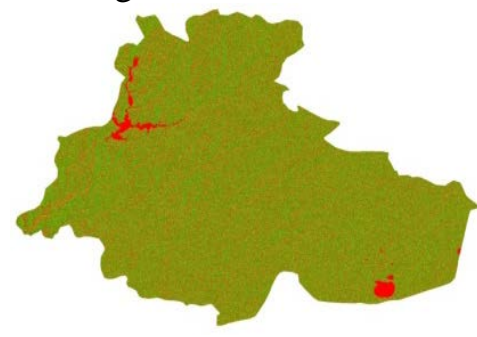

Slope

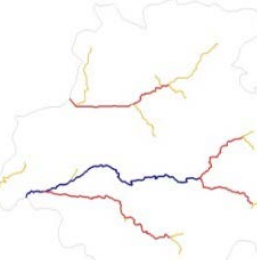

Flow accumulation

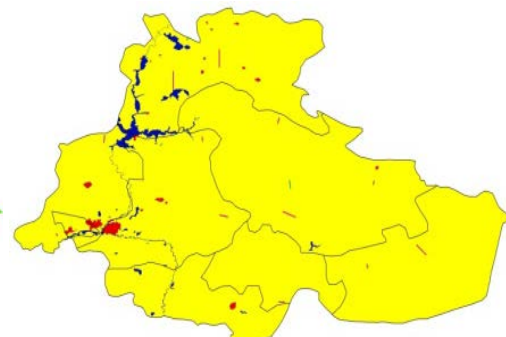

Geological structural

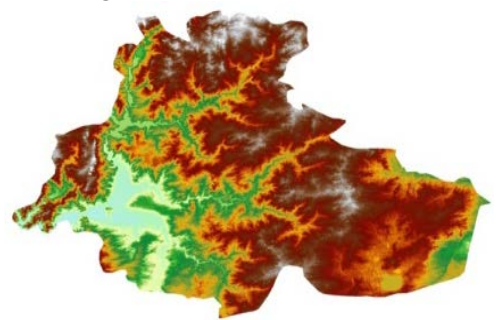

DEM

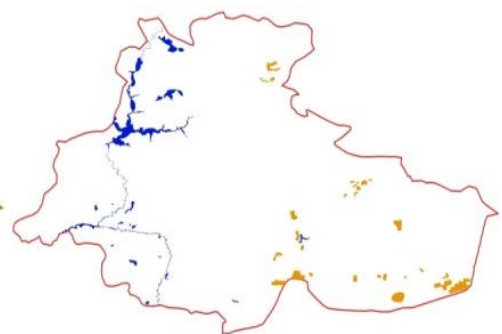

Lithology

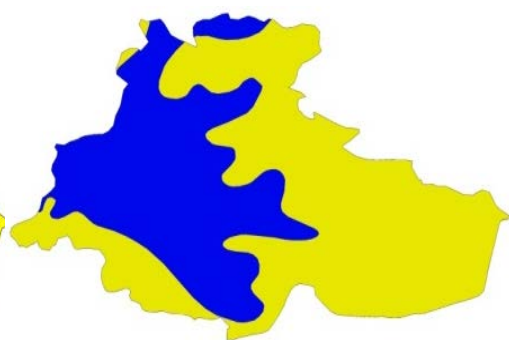

Geomorphology
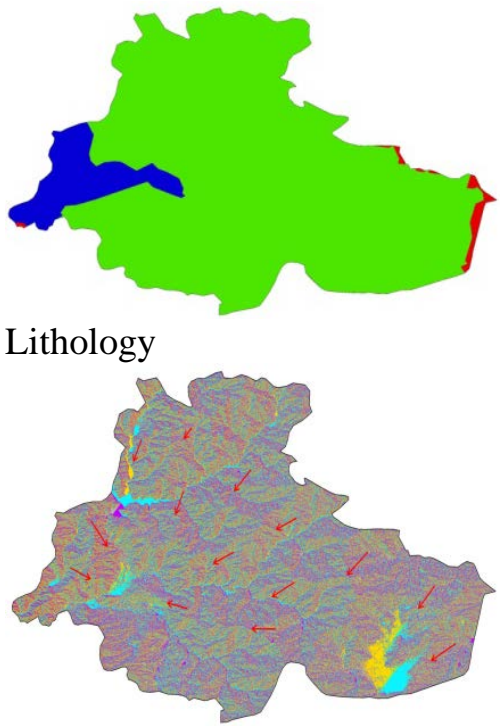

Flow direction

Surface water body

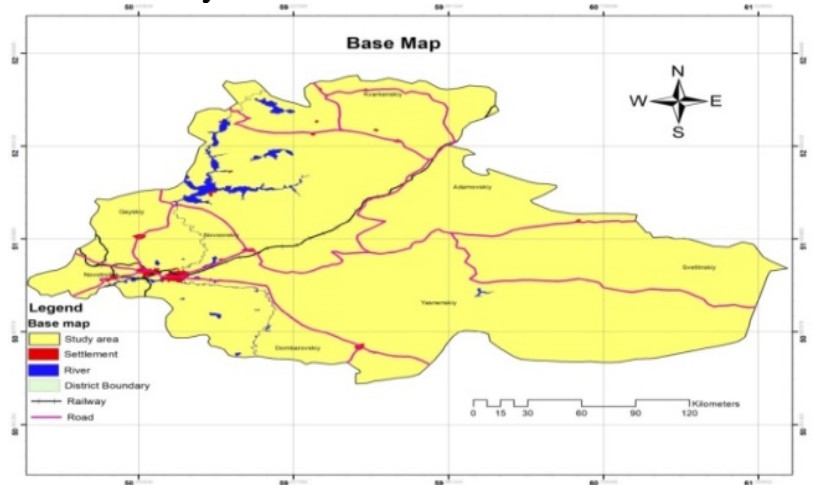

Figure 2. Thematic layers which used for groundwater potential zone mapping.

After creating above thematic layers, we combined all layers in ArcGIS software by using the raster calculator module to generate the final groundwater potential zone map of Orenburg, Russia. Than all factors in each thematic layer were given a specific weight (arithmetic value in between 1 to 9) based on its sensitivity or strength of influence to the groundwater possibility [8, 9, 10]. In last further, classify final groundwater potentiality map into five classes from very high to very low classes.

After giving specific weight to all factors, then calculate a normalized weight $(W n)$ by geometric mean $(G M)$ and in finally get groundwater potential zone map (GWPZ) using the following equations:

$$
W n=\left(G M n / \sum_{n=1}^{n f} G M n\right)
$$

Where the geometric mean of the $\mathrm{i}^{\text {th }}$ row of the judgment matrices is calculated as:

$$
G M n=\mathrm{n} \sqrt{\mathrm{p} 1 \mathrm{np} 2 \mathrm{n} \ldots \ldots \mathrm{pnNf}}
$$

The groundwater potential zone map was mathematically calculated using ArcGIS raster analysis as follows: 


$$
\begin{gathered}
G W P Z=\sum W i * R i, \\
E f=W i * R i
\end{gathered}
$$

$\mathrm{GWPZ}=\sum($ Ef of all thematic layers $)$

Where the meaning of equations words as follows:

- $E_{\mathrm{f}}=$ effectiveness of a factor for groundwater potentiality in the study area.

- $\mathrm{W}_{\mathrm{i}}=$ map weight for factor $\mathrm{i}$,

- $\mathrm{R}_{\mathrm{i}}=$ rating value for $\mathrm{i}$ factor.

Table 1. Calculation of factors weight.

\begin{tabular}{|c|c|c|c|c|c|c|c|c|c|c|c|c|c|}
\hline & $\mathbf{1}$ & $\mathbf{2}$ & $\mathbf{3}$ & $\mathbf{4}$ & $\mathbf{5}$ & $\mathbf{6}$ & $\mathbf{7}$ & $\mathbf{8}$ & $\mathbf{9}$ & $\mathbf{1 0}$ & $\mathbf{1 1}$ & GM & Wn \\
\hline $\mathbf{1}$ & 1.00 & 0.93 & 1.17 & 0.78 & 1.75 & 1.07 & 1.55 & 2.33 & 0.88 & 1.75 & 1.75 & 1.23 & 0.062 \\
\hline $\mathbf{2}$ & 1.07 & 1.00 & 1.25 & 0.83 & 1.87 & 1.15 & 1.66 & 2.50 & 0.93 & 1.87 & 1.87 & 1.31 & 0.067 \\
\hline $\mathbf{3}$ & 0.86 & 0.80 & 1.00 & 0.67 & 1.50 & 0.92 & 1.33 & 2.00 & 0.75 & 1.50 & 1.50 & 1.05 & 0.053 \\
\hline $\mathbf{4}$ & 1.29 & 1.20 & 1.50 & 1.00 & 2.25 & 1.38 & 2.00 & 3.00 & 1.13 & 2.25 & 2.25 & 1.58 & 0.080 \\
\hline $\mathbf{5}$ & 0.57 & 0.53 & 0.67 & 0.44 & 1.00 & 0.61 & 0.88 & 1.33 & 0.50 & 1.00 & 1.00 & 0.70 & 0.036 \\
\hline $\mathbf{6}$ & 0.92 & 0.86 & 1.08 & 0.72 & 1.62 & 1.00 & 1.44 & 2.16 & 0.81 & 1.62 & 1.62 & 1.14 & 0.058 \\
\hline $\mathbf{7}$ & 0.64 & 0.60 & 0.75 & 0.50 & 1.12 & 0.69 & 1.00 & 1.50 & 0.56 & 1.12 & 1.12 & 0.79 & 0.040 \\
\hline $\mathbf{8}$ & 0.43 & 0.40 & 0.50 & 0.33 & 0.75 & 0.46 & 0.66 & 1.00 & 0.38 & 0.75 & 0.75 & 0.53 & 0.027 \\
\hline $\mathbf{9}$ & 1.14 & 1.06 & 1.33 & 0.89 & 2.00 & 1.23 & 1.77 & 2.67 & 1.00 & 2.00 & 2.00 & 1.40 & 0.071 \\
\hline $\mathbf{1 0}$ & 0.57 & 0.53 & 0.67 & 0.44 & 1.00 & 0.61 & 0.88 & 1.33 & 0.50 & 1.00 & 1.00 & 0.70 & 0.036 \\
\hline $\mathbf{1 1}$ & 0.57 & 0.53 & 0.67 & 0.44 & 1.00 & 0.61 & 0.88 & 1.33 & 0.50 & 1.00 & 1.00 & 0.70 & 0.036 \\
\hline
\end{tabular}

\section{Results}

The eleven factors for groundwater potentiality mapping (land use/cove, geomorphology, geology, geological structure, elevation, slope, drainage density, surface water body, base map, flow accumulation, flow direction) were examined separately and describe in the following paragraphs.

4.1 Land use/cover: Land use/cover is one of the most important human-induced activity affecting the occurrence and development of groundwater. Inland use/cove, groundwater used for irrigation, industry and daily uses, etc. LULC map was classified in the water body, settlements, vegetation, and bare land. We assigned 0.062 weights to LULC map. As water body and vegetation have a high possibility of water, so assigned the highest rating. While bare and dry land area consider less significant so given lowest rating (table 1 \& figure 2).

4.2 Geomorphology: To prepare a geomorphology map, we used ancillary data, satellite imagery, lithology map, land use map, and field data. For satellite image interpretation, we used interpretation key such as tone, texture, color, shape, and size, etc. In the final geomorphology map, we assigned 0.053 weights and reclassify the whole map in 5 classes based on groundwater possibility (table $1 \&$ figure 2).

4.3 Geology: Geology layer assigned 0.067 weights. Geological structure map was derived from ancillary data and available geological maps. The whole map was divided into 5 classes according to their possibility of storage groundwater capacity (table 1 \& figure 2).

4.4 Geological structure: Geology layer assigned 0.080 weights. In lithology fractures, joins, dikes and porosity are influencing features to increase groundwater storage capacity. The sedimentary aquifers with primary porosity have higher groundwater storage capacity. The lithology map was derived from ancillary data and available geological maps. The whole map was divided into 5 classes according to their possibility of storage groundwater capacity (table 1 \& figure 2 ).

4.5 Elevation: We prepared an elevation map from ASTER-GDEM, the elevation is directly related to the ruggedness of the terrain, which has a major role in the identification of groundwater. A planning area or lower elevation with steep slope has smaller runoff, less drainage, higher infiltration rate so higher possibility of groundwater. In the study area, high elevation area has high groundwater possibility due to a higher amount of rainfall. Kalmykia has $-103 m$ lowest and 
$285 \mathrm{~m}$ highest elevation point. The study area can be divided into 5 major classes as (1) higher then $>120$, (2) 120 to 70, (3) 70 to 25, (4) 25 to -6 , and less then < - 6. Elevation layer assigned 0.036 weights (table 1 \& figure 2 ).

4.6 Slope: Slope is directly related to groundwater because, in high slope, water velocity is high so infiltration rate is low so overall groundwater recharge possibility is low. In the other hand in lower slop, the infiltration rate is high due to low water velocity so greater chance of groundwater recharge. Slope map was prepared by ASTER-GDEM data in ArcGIS software and assigned 0.058 weights (table $1 \&$ figure 2 ).

4.7 Drainage density: We used ASTER-GDEM data to prepare drainage map and later on create drainage density map via "line density" commend in ArcGIS software and in last reclassify it into 5 classes from very low to very high (table $1 \&$ figure 2). Drainage network produces a dendritic pattern, resulting in water flow in a homogenous soil surface with the same geological conditions. The denser the drainage has the less capacity of groundwater recharge and vice versa. We assigned 0.40 weights to drainage density layer.

4.8 Base map: Base map also directly relevant to the possibility of groundwater as in study area where is a higher possibility of vegetation such as agriculture, forest and plantation show green areas. In another side, less vegetation cover area shows desert or drought areas (east-south) have less possibility of groundwater (figure 2).

4.9 Surface water: Surface waterbody is directly related to groundwater possibility. If an area has a higher number of surface water bodies then it might be a higher possibility of groundwater. Surface water assigned 0.71 weights (table $1 \&$ figure 2 ).

4.10 Flow accumulation: We used ASTER-GDEM data to prepare a flow accumulation map in ArcGIS software and reclassify it into 5 classes from very low to very high (figure 2). Low accumulation values represent ridge tops so less possibility of groundwater due to low infiltration, steep slow, and higher water flow. Whereas higher accumulation values represent valleys and stream channels so a higher possibility of groundwater due to high infiltration. Flow accumulation assigned 0.036 weights (table 1 \& figure 2).

4.11 Flow direction: Flow direction map gives us the flow across a surface which will always be in the steepest down-slope direction and is used to determine the stream network. Flow direction map created from ASTER-GDEM grid shows the direction of river flow from northeast to southwest and finally reached in Caspian sea. We assigned 0.036 weights to flow direction map (table 1 \& figure 2).
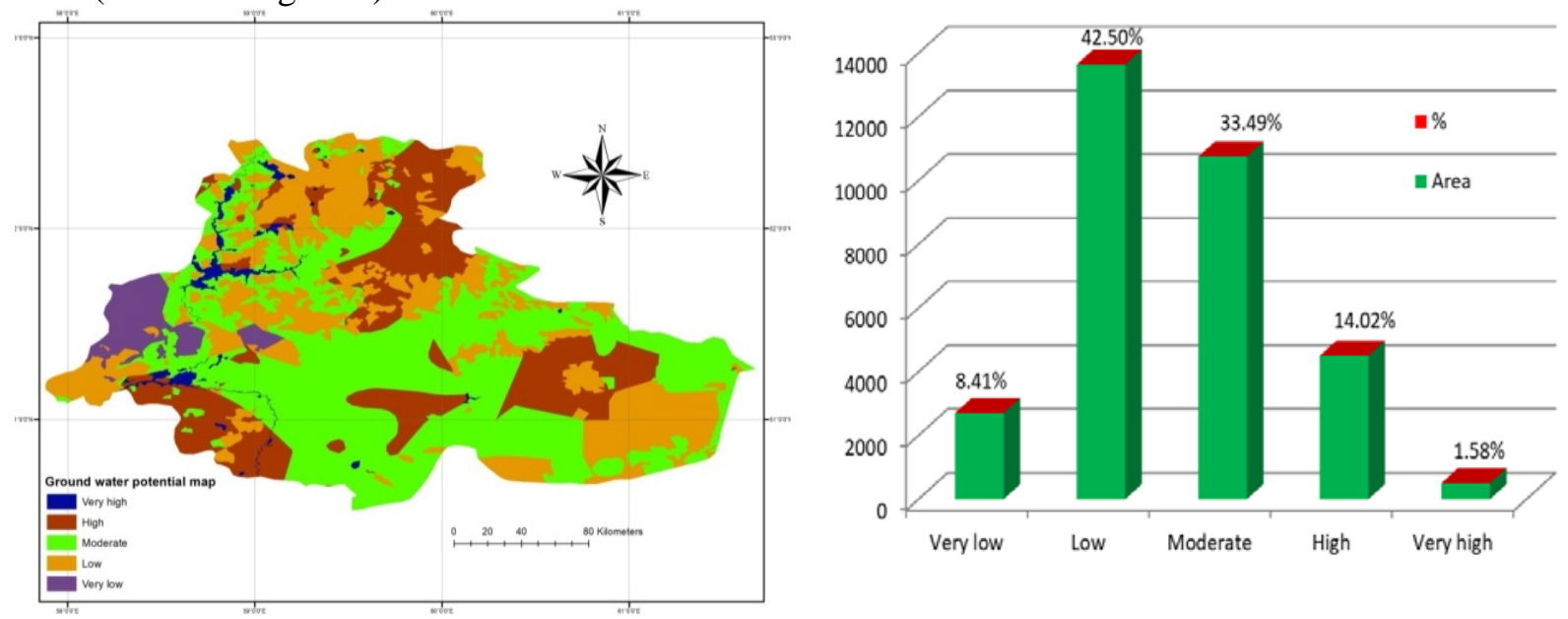

Figure 3. Groundwater potential map of Orenburg, Russia.

Finally after combined all thematic layers, we get groundwater potential zone map of Orenburg (figure 3) with five classes from very high to very low possibility of groundwater. Approximately 16\% of the study area in the northwest part comes under high and a very high class, means they have the maximum possibility of groundwater. Generally, low elevations, less slop, low drainage density have high soil porosity which increases high infiltration rate of water so its increase the groundwater 
possibility $[11,12]$. Around 33\% study area show the moderate possibility of groundwater. The north part of the study area comes under low water possibility due to its higher slop, unfavorable geological and geomorphological conditions and covers $42.50 \%$ area of the study site (figure 3 ).

\section{Conclusion}

This research work generates groundwater potential zone map of Orenburg, Russia by combined different thematic layers, which relevant to groundwater possibility by giving them specific weight in RS and GIS technology. Recent year's groundwater resources mapping has been increasing due to increased demand for water for different purposes.

\section{References}

[1] Minor T, Carter J 1994 The use of GIS and remote sensing in groundwater exploration for developing countries Proceedings of the tenth thematic conference on geologic remote sensing (San Antonio, Texas, USA, Environmental Research Institute of Michigan, Ann Arbor) MI

[2] Gustafsson P 1993 High resolution satellite data and GIS as a tool for assessment of groundwater potential of semiarid area IXth thematic conference on geologic remote sensing 1 609-619

[3] Krishnamurthy J, Venkatesesa K N 1996 An approach to demarcate groundwater potential maps through remote sensing and GIS Int J Remote Sens 7 1867-1884

[4] Das P, Bahara S C 1997 Hydrogeomorphological mapping in ground water exploration using remotely sensed data - a case study in Keunjhar District, Orissa J Ind Soc Remote Sens 25(4) 247-260

[5] Laishram K S, Madan K Jha and Chowdary V M 2018 Assessing the accuracy of GIS-based Multi-Criteria Decision Analysis approaches for mapping groundwater potential Ecological Indicators 91 24-37

[6] Choudhary K, Boori M S and Kupriyanov A 2017 Spatio-temporal analysis through remote sensing and GIS in Moscow region, Russia CEUR Workshop Proceedings 1901 42-46

[7] Agarwal R, Garg P K 2016 Remote sensing and GIS based groundwater potential \& recharge zones mapping using multi-criteria decision making technique Water Resource Management 30(1) 243-260

[8] Choudhary K, Boori M S and Kupriyanov A 2017 Mapping and evaluating urban density patterns in Moscow, Russia Computer Optics 41(4) 528-534 DOI: 10.18287/2412-6179-201741-4-528-534

[9] Pavelyeva E A 2018 Image processing and analysis based on the use of phase information Computer Optics 42(6) 1022-1034 DOI: 10.18287/2412-6179-2018-42-6-1022-1034

[10] Choudhary K, Boori M S and Kupriyanov A 2017 mapping and evaluating urban density patterns in Moscow, Russia Computer Optics 41(4) 528-534 DOI: 10.18287/2412-6179-201741-4-528-534

[11] Bibikov S A, Kazanskiy N L and Fursov V A 2018 Vegetation type recognition in hyperspectral images using a conjugacy indicator Computer Optics 42(5) 846-854 DOI: 10.18287/2412-6179-2018-42-5-846-854

[12] Belov A M, Denisova A Y 2018 Spectral and spatial super-resolution method for earth remote sensing image fusion Computer Optics 42(5) 855-863 DOI: 10.18287/2412-6179-2018-42-5855-863

\section{Acknowledgments}

This work was partially supported by the Ministry of education and science of the Russian Federation in the framework of the implementation of the Program of increasing the competitiveness of Samara University among the world's leading scientific and educational centers for 2013-2020 years; by the Russian Foundation for Basic Research grants (\# 15-29-03823, \# 16-41-630761, \# 17-01-00972, \# 1837-00418), in the framework of the state task \#0026-2018-0102 "Optoinformation technologies for obtaining and processing hyperspectral data". 